\title{
Efficacy of pasireotide in controlling severe hypercortisolism until cardiac transplantation
}

\author{
Roberto Attanasio1,2, Liana Cortesi', Daniela Gianola', Claudia Vettori³, \\ Fulvio Sileo ${ }^{1}$ and Roberto Trevisan' ${ }^{1}$ \\ 'Endocrinology Service, Galeazzi Institute IRCCS, Milan, Italy, ${ }^{2}$ Endocrinology and Diabetology, and \\ ${ }^{3}$ Cardiology, Papa Giovanni XXIII Hospital, Bergamo, Italy
}

\author{
Correspondence \\ should be addressed \\ to R Attanasio \\ Email
}

roberto.serena@libero.it

\section{Summary}

Cushing's syndrome is associated with increased morbidity and mortality. Although surgery is the first-line treatment, drugs can still play a role as an ancillary treatment to be employed while waiting for surgery, after unsuccessful operation or in patients unsuitable for surgery. We were asked to evaluate a 32-year-old male waiting for cardiac transplantation. Idiopathic hypokinetic cardiomyopathy had been diagnosed since 6 years. He was on treatment with multiple drugs, had a pacemaker, an implantable cardioverter and an external device for the support of systolic function. Physical examination showed severely impaired general status, signs of hypercortisolism and multiple vertebral compression fractures. We administered teriparatide, and the few evaluable parameters supported the diagnosis of ACTH-dependent hypercortisolism: serum cortisol was $24.2 \mu \mathrm{g} / \mathrm{dL}$ in the morning and $20.3 \mu \mathrm{g} / \mathrm{dL}$ after overnight $1 \mathrm{mg}$ dexamethasone, urinary free cortisol (UFC) was $258 \mu \mathrm{g} / 24 \mathrm{~h}$ and ACTH $125 \mathrm{pg} / \mathrm{mL}$. Pituitary CT was negative. Pasireotide $300 \mu \mathrm{g}$ bid was administered and uptitrated to $600 \mu \mathrm{g}$ bid. Treatment was well tolerated, achieving dramatic improvement of clinical picture with progressive normalization of serum cortisol and ACTH levels as well as UFC. After 4 months, the patient underwent successful heart transplantation. Many complications ensued and were overcome. Pituitary MRI was negative. On pasireotide $300 \mu \mathrm{g}$ bid and prednisone $2.5 \mathrm{mg} / \mathrm{day}$ (as part of immunosuppressive therapy), morning serum cortisol and ACTH were $15.6 \mu \mathrm{g} / \mathrm{dL}$ and $54 \mathrm{pg} / \mathrm{mL}$ respectively, UFC was $37 \mu \mathrm{g} / 24 \mathrm{~h}$, fasting glucose: $107 \mathrm{mg} / \mathrm{dL}$ and HbA1c: $6.5 \%$. In conclusion, primary treatment with pasireotide achieved remission of hypercortisolism, thus allowing the patient to undergo heart transplantation.

\section{Learning points:}

- Untreated Cushing's syndrome is associated with ominous prognosis.

- First-line treatment is surgery (at pituitary or adrenal, according to disease localization).

- A few drugs are available to treat hypercortisolism.

- Pasireotide is a multi-ligand somatostatin analog approved for treatment of hypercortisolism.

- Primary treatment with pasireotide was effective in a patient with severe Cushing's syndrome, allowing him to undergo heart transplantation.

\section{Background}

Cushing's syndrome (CS) is a chronic disabling disease due to hypercortisolism, leading to increased morbidity and mortality (1).

After exclusion of the most frequent iatrogenic form, CS can be classified in ACTH-independent (about 20\%, due to adrenal adenoma or carcinoma or rare bilateral nodular types) and ACTH-dependent types. The latter group, accounting for $80 \%$ of the whole spectrum of endogenous hypercortisolism, is composed of ACTH-secreting pituitary adenomas in most cases 
(the true Cushing's disease, CD) or ectopic ACTH (or rarely $\mathrm{CRH}$ ) secreted by ectopic tumors in about onethird of cases. In addition, CS occasionally occurs in genetic multi-glandular diseases or may have cyclic behavior alternating between activity and remission at daily, weekly or even monthly intervals (2).

Clinical management of CS is often a challenge. Diagnosis could be challenging requiring that skillful clinicians put together results of a step-to-step workup (3). The first step is the diagnosis of CS, ruling out iatrogenic hypercortisolism and the so-called pseudo-Cushing's, a form of functional hypercortisolism (due to severe obesity, alcoholism or depression) that may mimic CS. The second step is the differentiation between ACTHdependent and -independent forms of hypercortisolism. The third step is the differential diagnosis among the components of each group, by hormonal dynamic tests and imaging studies. Although guidelines could help, this diagnostic process entails tips and tricks; for example, ACTH-secreting adenomas are often small, below the resolution of conventional MRI and a microadenoma can occur in about $15 \%$ of the normal population (the so-called incidentaloma) (4).

An accurate diagnosis is a pre-requisite for optimal treatment. Surgery is the first-line treatment for any type of CS (5). Drugs can still play a role as an ancillary form of treatment to be employed in patients unsuitable for surgery or while waiting for surgery or after unsuccessful operation (5). Drugs can act at three different levels: at the pituitary level by inhibiting ACTH secretion, at the adrenal level by inhibiting steroidogenesis and at the glucocorticoid receptor by inhibiting steroid action. Beyond a wide array of outdated or still investigational compounds, these categories are now represented by cabergoline (6) and pasireotide (7), ketoconazole and metyrapone (8) and mifepristone (9) respectively. Each drug has specific advantages and side effects, but none can be regarded as the optimal choice in every patient.

\section{Case presentation}

A 32-year-old male was hospitalized in the Cardiology Department of our Hospital waiting for heart transplantation due to an idiopathic hypokinetic cardiomyopathy with hyperhomocysteinemia.

This diagnosis was made 6 years earlier after a cerebral infarction, treated with systemic thrombolysis followed by warfarin. Anticoagulation was withdrawn after cerebral hemorrhage with seizures. He had gallstones and multinodular goiter and had been treated with methimazole for amiodarone-induced thyrotoxicosis. At admission, medications included bisoprolol, amlodipine, ramipril, canrenoate, aspirin, warfarin, folic acid, atorvastatin and levetiracetam. He also had a permanent pacemaker, an implantable cardioverter and an external device for the support of systolic function.

As endocrinologists, we were asked to evaluate the patient for suspect hypercortisolism. Physical examination showed severely impaired general status as well as facial plethora, thin skin and bruising, and multiple vertebral compression fractures. Teriparatide was administered and only a minimal workup could be performed due to the severe clinical conditions, multiple ongoing drugs and the presence of multiple implanted devices. UFC was $258 \mu \mathrm{g} / 24 \mathrm{~h}$, morning serum cortisol $24.2 \mu \mathrm{g} / \mathrm{dL}$ in basal conditions and $20.3 \mu \mathrm{g} / \mathrm{dL}$ after overnight $1 \mathrm{mg}$ dexamethasone and ACTH $125 \mathrm{pg} / \mathrm{mL}$. Serum sodium, potassium, prolactin, TSH and FT4 were within normal limits; testosterone was low $(1.9 \mathrm{ng} / \mathrm{mL})$ with low gonadotropin levels (LH: 1.6U/L and FSH: 6.6U/L). CT was negative at the pituitary level.

The few parameters supported thus the diagnosis of ACTH-dependent hypercortisolism. No further diagnostic procedures could be performed to differentiate between ACTH-secreting adenoma and ectopic ACTH secretion.

Available options for a medical therapy were thoroughly discussed in a multidisciplinary panel. Mifepristone (9) is not allowed in our country for this indication and is difficult to manage in the absence of any reliable biochemical parameter to monitor its effectiveness. Ketoconazole was not regarded as a suitable option due to liver toxicity (8). Metyrapone (8) was not yet available in our country, and cabergoline (6) is effective only in a minority of patients with CD and is 'off label' for this indication. Only pasireotide remained on the stage and was thus administered at a dose of $300 \mu \mathrm{g}$ bid and uptitrated to $600 \mu \mathrm{g}$ bid. Treatment was well tolerated, achieving dramatic improvement of clinical picture with progressive normalization of hormonal parameters: UFC and ACTH reached $30 \mu \mathrm{g} / 24 \mathrm{~h}$ and $52 \mathrm{pg} / \mathrm{mL}$ respectively. Transient hypoadrenalism occurred (suggestive clinical picture with nausea, vomiting and fatigue, and morning serum cortisol $9.8 \mu \mathrm{g} / \mathrm{dL}$ ) and reverted after transient down-titration of pasireotide. Glucose metabolism was not deranged (fasting glucose range: $100-120 \mathrm{mg} / \mathrm{dL}$ ).

After 4 months, the patients underwent heart transplantation. Many post-transplant complications occurred (hemorrhagic shock due to femoral artery 
rupture, three episodes of acute rejection, massive cerebral bleeding requiring transcranial neurosurgery and pneumonia), but they were adequately treated, including treatment with high-dose steroids. Secondary diabetes due to high-dose steroids was treated with insulin. Pasireotide was never withdrawn. Testosterone levels were spontaneously recovered (up to $3.3 \mathrm{ng} / \mathrm{mL}$ ).

Pituitary MRI was negative. On pasireotide $300 \mu \mathrm{g}$ bid and prednisone $2.5 \mathrm{mg} /$ day (as part of antirejection protocol, beyond insulin - $17 \mathrm{U}$ in four shots-, mycofenolate mofetil, cyclosporine, amlodipine, enalapril, levetiracetam, frusemide, theophylline, ursodeoxycholic acid, L-thyroxine, and omeprazole), morning serum cortisol and ACTH were $15.6 \mu \mathrm{g} / \mathrm{dL}$ and $54 \mathrm{pg} / \mathrm{mL}$ respectively, and UFC was $37 \mu \mathrm{g} / 24 \mathrm{~h}$, fasting glucose $100 \mathrm{mg} / \mathrm{dL}$ and $\mathrm{HbA} 1 \mathrm{c} 42 \mathrm{mM} / \mathrm{M}$.

\section{Methods}

UFC was assayed (after extraction with methylene chloride) by chemiluminescence (Liaison, Diasorin, Saluggia, Italy). Normal values are $10-90 \mu \mathrm{g} / 24 \mathrm{~h}$, interassay coefficients of variation are 4.8-9.3\% (at normal and high concentrations respectively). Cross-reactivity with prednisone is $0.4 \%$.

Serum cortisol was assayed by chemiluminescence (Advia Centaur, Siemens), with internal standard calibrated against analytes of gas chromatography-mass spectrometry and a detection limit of $0.2 \mu \mathrm{g} / \mathrm{dL}$; normal morning values are $4-23 \mu \mathrm{g} / \mathrm{dL}$. Inter-assay coefficients of variation are 1.86, 5.45, 3.99\% (at normal, low and high concentrations respectively). Cross-reactivity with prednisone is $6.6 \%$.

ACTH was assayed by chemiluminescence (Immulite 2000, Siemens), with an internal standard, and a detection limit of $5 \mathrm{pg} / \mathrm{mL}$; normal morning values are $<46 \mathrm{pg} / \mathrm{mL}$.

\section{Discussion}

It is well known that the diagnosis of CS is a difficult task even for skilled clinicians (3). We report here the rare case of a young patient in waiting list for heart transplantation with a clinical picture highly suggestive for CS.

A complete workup could not be performed due to severe clinical conditions, ongoing multidrug treatment that could not be withdrawn and implantable devices, which were contraindications to MRI. Despite this difficult clinical setting, the minimal biochemistry that could be performed (showing high non-suppressible cortisol levels and high ACTH levels) supported the diagnosis of an ACTH-dependent endogenous hypercortisolism. The next step in the diagnostic workup, i.e. the differential diagnosis between ACTH-secreting pituitary microadenoma and ectopic ACTH (or CRH) secretion, could not be accomplished. The former is more frequent in the age group of the patient, but this is not a rule (3).

Given the severe condition of the patient, a therapeutic choice was thus compelling. Even though surgery is the first-line treatment in hypercortisolism (5), an alternative option was mandatory as the severity of heart disease precluded any surgical procedure (i.e. an exploration at the pituitary level or a bilateral adrenalectomy) (10). Radiosurgery was not an option due to the lack of target and slowness of action requiring years (11).

Available options for a medical therapy were discussed in a multidisciplinary panel leading to the choice of pasireotide, a somatostatin analog active on different somatostatin receptors. Pasireotide was approved in Europe and US after a prospective multicentric study (7) and showed its efficacy at the dose of 600 or $900 \mu \mathrm{g}$ bid in reducing UFC levels up to normalization in 15-26\%. It has a relatively rapid action, achieving results in a few weeks. Its main side effect is the derangement of glucose metabolism, although many drugs are now available to reduce high glucose levels.

Pasireotide was effective in our patient both at the clinical level and in normalizing hypercortisolism. Treatment was well tolerated without any derangement of glucose metabolism, liver or kidney parameters.

After the normalization of cortisol metabolism, the patient underwent successful heart transplantation. We decided to carry on pasireotide treatment even after an acute graft rejection treated by high-dose steroids, in the belief that steroid treatment would have been more easily manageable with the suppression of endogenous steroid secretion.

We cannot rule out with certainty that other complications ensued in the patient were due to pasireotide, but this seems unlikely in light of recovery despite ongoing treatment.

Workup after the stabilization of the patient confirmed the diagnosis of ACTH-dependent hypercortisolism. MRI was negative, as often observed in $\mathrm{CD}$, but dynamic tests could not yet be performed for ethical reasons, owing to clinical conditions of the patient that hampered ongoing treatment withdrawal. Pasireotide is not approved for treatment of neuroendocrine tumors (NET) at this time although there has been some evidence of efficacy. Ectopic ACTH production from a NET was not formally ruled out in our patient, but that diagnosis seems highly unlikely. 
The clinical outcome of this case report confirms the recent data by Cannavò et al. (12) on effective presurgical pasireotide treatment of $\mathrm{CD}$ in two critically ill patients.

In conclusion, we show here for the first time the efficacy of pasireotide as a bridge treatment for ACTHdependent hypercortisolism in a severely ill patient, even in the absence of a precise diagnosis.

\section{Declaration of interest}

The authors declare that there is no conflict of interest that could be perceived as prejudicing the impartiality of the research reported.

\section{Funding}

This research did not receive any specific grant from any funding agency in the public, commercial or not-for-profit sector.

\section{Patient consent}

Written informed consent has been obtained from the patient for publication of the submitted article.

\section{Author contribution statement}

Roberto Attanasio wrote the paper; Liana Cortesi, Daniela Gianola and Fulvio Sileo served as endocrine consultants; Claudia Vettori took care of the patient and Roberto Trevisan is the director of the endocrine unit.

\section{References}

1 Arnaldi G, Mancini T, Tirabassi G, Trementino L \& Boscaro M 2012 Advances in the epidemiology, pathogenesis, and management of Cushing's syndrome complications. Journal of Endocrinological Investigation 35 434-448. (doi:10.1007/BF03345431)

2 Newell-Price J, Trainer P, Besser M \& Grossman A 1998 The diagnosis and differential diagnosis of Cushing's syndrome and pseudo-Cushing's states. Endocrine Reviews 19 647-672. (doi:10.1210/er.19.5.647)
3 Nieman LK, Biller BMK, Findling JW, Newell-Price J, Savage MO, Stewart PM \& Montori VM 2008 The diagnosis of Cushing's Syndrome: an Endocrine Society clinical practice guideline. Journal of Clinical Endocrinology and Metabolism 93 1526-1540. (doi:10.1210/ jc.2008-0125)

4 Freda PU, Beckers AM, Katznelson L, Molitch ME, Montori VM, Post KD, Vance ML \& Endocrine Society 2011 Pituitary incidentaloma: an endocrine society clinical practice guideline. Journal of Clinical Endocrinology and Metabolism 96 894-904. (doi:10.1210/jc.2010-1048)

5 Niemann LK, Biller BMK, Findling JW, Murad MH, Newell-Price J, Savage MO \& Tabarin A 2015 Treatment of Cushing's syndrome: an Endocrine Society clinical practice guideline. Journal of Clinical Endocrinology and Metabolism 100 2807-2831. (doi:10.1210/jc.20151818)

6 Lila AR, Gopal RA, Acharya SV, George J, Sarathi V, Bandgar T, Menon PS \& Shah NS 2010 Efficacy of cabergoline in uncured (persistent or recurrent) Cushing disease after pituitary surgical treatment with or without radiotherapy. Endocrine Practice 16 968-976. (doi:10.4158/EP10031.OR)

7 Colao A, Petersenn S, Newell-Price J, Findling JW, Gu F, Maldonado M, Schoenherr U, Mills D, Salgado LR \& Biller BM, for the Pasireotide B2305 Study Group 2012. A 12-month phase 3 study of pasireotide in Cushing's disease. New England Journal of Medicine 366 914-924. (doi:10.1056/nejmoa1105743)

8 Daniel E \& Newell-Price JD 2015 Therapy of endocrine disease: steroidogenesis enzyme inhibitors in Cushing's syndrome. European Journal of Endocrinology 172 R263-R280. (doi:10.1530/EJE-14-1014)

9 Fleseriu M, Biller BM, Findling JW, Molitch ME, Schteingart DE \& Gross C, on behalf of the SEISMIC Study Investigators 2012 Mifepristone, a glucocorticoid receptor antagonist, produces clinical and metabolic benefits in patients with Cushing's syndrome. Journal of Clinical Endocrinology and Metabolism 97 2039-2049. (doi:10.1210/ jc.2011-3350)

10 Reincke M, Ritzel K, Oßwald A, Berr C, Stalla G, Hallfeldt K, Reisch N, Schopohl J \& Beuschlein F 2015 A critical reappraisal of bilateral adrenalectomy for ACTH-dependent Cushing's syndrome. European Journal of Endocrinology 173 M23-M32. (doi:10.1530/EJE-15-0265)

11 Oyesiku NM 2007 Stereotactic radiosurgery for Cushing disease: a review. Neurosurgical Focus 23 E14. (doi:10.3171/foc-07/12/e14)

12 Cannavò S, Messina E, Albani A, Ferraù F, Barresi V, Priola S, Esposito F \& Angileri F 2016 Clinical management of critically ill patients with Cushing's disease due to ACTH-secreting pituitary macroadenomas: effectiveness of presurgical treatment with pasireotide. Endocrine 52 481-487. (doi:10.1007/s12020015-0601-2)

Received in final form 26 January 2017 Accepted 8 February 2017 